\title{
Improving habitat models by incorporating pelagic measurements from coastal ocean observatories
}

\author{
Laura Palamara ${ }^{1, *}$, John Manderson ${ }^{2}$, Josh Kohut $^{1}$, Matthew J. Oliver ${ }^{3}$, \\ Steven Gray ${ }^{4}$, John Goff ${ }^{5}$
}

\author{
${ }^{1}$ Institute of Marine and Coastal Sciences, Rutgers University, New Brunswick, New Jersey 08901, USA \\ ${ }^{2}$ NOAA, National Marine Fisheries Service, Northeast Fisheries Science Center, Ecosystems Processes Division, \\ James J. Howard Marine Sciences Laboratory, Highlands, New Jersey 07732, USA \\ ${ }^{3}$ College of Earth, Ocean and Environment, University of Delaware, Lewes, Delaware 19958, USA \\ ${ }^{4}$ Department of Natural Resources and Environmental Management, University of Hawaii, \\ Honolulu, Hawaii 96822, USA \\ ${ }^{5}$ Institute for Geophysics, Jackson School of Geosciences, University of Texas at Austin, Austin, Texas 78758, USA
}

\begin{abstract}
As in all temperate coastal seas, habitats in the Mid-Atlantic Bight are spatially and temporally dynamic. Understanding how species respond to the dynamics of their environment is important for developing effective management strategies. In this study, we used canonical correspondence analysis (CCA) to determine habitat variables most important in explaining variation in fish and invertebrate communities sampled with bottom trawls. We also quantified the relative explanatory power of seabed habitat features, pelagic features measured in situ and pelagic features measured remotely, all of which can be used to explain species variability. Pelagic habitat features, most notably surface and bottom temperature and stratification, explained $76 \%$ of the community variation observed, compared with $40.9 \%$ explained by seabed features, mainly depth. Remotely sensed pelagic characteristics explained $46.9 \%$ of the variation that was accounted for and were redundant for features measured in situ; this suggests that remotely sensed features are representative of features measured in situ including certain subsurface features. Cross-shelf and seasonal variation in environmental variables were the major predictors of species distributions and accounted for $71.3 \%$ of the total explained community variation. We described the seasonal dynamics of important habitat gradients and the responses of species with different habitat requirements and geographic range distributions to those gradients. We argue that consideration of dynamic pelagic features in addition to slowly changing features is important. Dynamic approaches are necessary for effective management and ocean observing systems can be used to develop dynamic space-based management strategies.
\end{abstract}

KEY WORDS: Habitat characteristics - Pelagic - Remote sensing - Spatial fisheries management · Canonical correspondence analysis $\cdot$ CCA $\cdot$ Mid-Atlantic Bight

\section{INTRODUCTION}

Spatial distributions of many species are largely a result of behavioral habitat selection along environmental gradients that are variable in both space and time. The factors that define habitat for mobile marine ectotherms, including circulation, temperature, primary and secondary productivity and seabed habitat structure, regulate growth, dispersal, survival and re- productive success. These habitat effects on the vital rates of individuals influence the productivity and stability of regional populations and communities (Fry 1971, Yamashita et al. 2001). In temperate areas like the Mid-Atlantic Bight (MAB), off the Atlantic coast of the USA, important habitat characteristics vary in space at daily, monthly, seasonal, annual and decadal time scales. Many species in this temperate region are highly migratory at different life stages in response to 
frequent and dramatic changes in the environment. In the short term the animals move to optimal habitats in new areas rather than remaining in the same location and adapting to new environmental conditions (Nye et al. 2009, Lucey \& Nye 2010). They use a variety of habitats at different times in their life cycles and at different times of year. To develop effective spaceand time-based conservation strategies, it is important to understand how animal populations respond to changing habitat components like temperature (Yamashita et al. 2001), circulation (Bakun 2010) and primary production (Yamashita et al. 2001).

There is a tendency to concentrate on seabed characteristics when describing habitats selected by marine species. However, characteristics of ocean habitats are strongly defined by the pelagic environment for both bottom-dwelling and pelagic species (Manderson et al. 2011). Many species spend at least part of their life cycle in the water column - often during the most sensitive early stages, when they suffer the highest mortality rates (Houde 2009) — and/or have prey that rely on water column characteristics (Yamashita et al. 2001). Even benthic species, which are also nearly neutrally buoyant, are strongly linked to many pelagic habitat features and processes that affect both intrinsic (e.g. temperature, form drag) and extrinsic (prey distribution) bioenergetic processes. Marine species are directly affected by pelagic characteristics in all life history stages; their metabolism depends largely on temperature, the transport of individuals (especially during early life stages) can be aided by currents and the productivity of the system can be affected by many pelagic factors including the mixing of the water column. Because of this, seascapes and the habitats that comprise them need to be evaluated in 3 dimensions. Inclusion of variables that describe water column processes, properties and structures in addition to seabed variables in habitat models should give more complete descriptions of marine species-environment relationships, which are useful for ecosystem analysis and development of space-based management strategies.

It has been difficult to measure water column habitat factors over ecologically relevant large spatial but fine time scales because of the difficulty and cost in regularly sampling the ocean at synoptic scales. The implementation of ocean observation systems, such as the Integrated Ocean Observing System (IOOS), overcomes this difficulty by sampling many important habitat variables on the required scales. For example, Bakun (2010) described 3 major classes of physical processes important for yielding ideal reproductive habitat for coastal fishes: processes of en- richment (i.e. upwelling and mixing), concentration (i.e. convergence and formation of fronts) and retention within or advection toward nursery grounds, each of which involves several pelagic features and processes best described by remotely sensed currents and fronts. IOOS can also be used to describe what is in the water and can sometimes be used to estimate the amount of food (primary productivity) in the area. By considering dynamic water column features and processes that can be measured both in situ and remotely with comparatively stable seabed features, we can more precisely describe the 3-dimensional structure of the environment to which marine species respond (Game et al. 2009).

The technology that IOOS uses to detect these pelagic variables remotely includes satellites (i.e. sea surface temperature and ocean color), high frequency (HF) radar (i.e. sea surface currents) and gliders (i.e. water column temperature, salinity, optical backscatter). These data streams are analyzed to produce derived variables such as chlorophyll, water mass boundaries and surface divergence. Satellites and HF radar provide the greatest amount of spatial coverage and include synoptic maps of surface currents, temperature and chlorophyll. These fields can be combined to map the location and relative strength of water mass boundaries (Oliver et al. 2004, Oliver \& Irwin 2008). While these observations are confined to the near-surface of the ocean, they are often indicative of the subsurface environment, especially during the winter and spring when the water column is well mixed in the MAB (Castelao et al. 2008). The increasing availability and coverage of various types of remotely sensed data in the MAB allow us to examine the relationships between fish and the pelagic environment that until now could not be studied in the region.

In the present study we combined measurements of habitat features on the bottom and in the water column to identify important species-habitat relationships in the MAB coastal ocean. We built statistical relationships between fish abundances and habitat characteristics likely to affect the growth, survival, dispersal and reproduction of marine species. Abundances were measured by the National Marine Fisheries Service, Northeast Fisheries Science Center's (NMFS-NEFSC) bottom trawl surveys, and habitat characteristics were measured with remote sensing and in situ technologies. Remotely sensed data were provided by the Mid-Atlantic Regional Association Coastal Ocean Observing System (MARACOOS) (www.maracoos.org), a regional association of IOOS. This study consisted of 3 major components: (1) a determination of the environmen- 
tal variables most strongly correlated with variations in fish and invertebrate abundance; (2) a quantification of the independent and joint effects on fish and invertebrate community structure of environmental variables in 3 categories - seabed variables, pelagic variables measured in situ (from conductivity, temperature and depth profiles) and pelagic variables measured with remote sensing technology; and (3) a description of the spatial structure of environmental gradients and responses of species with northern and southern species ranges and associations with the seabed or water column. Our goals were to identify habitat-defining environmental characteristics in the $\mathrm{MAB}$, examine the effectiveness of remote sensing technology for measuring those characteristics and provide baseline information for IOOS-informed space-based ecosystem management.

\section{MATERIALS AND METHODS}

\section{Study area}

The MAB extends from Cape Cod, Massachusetts, USA, to Cape Hatteras, North Carolina, USA. Physical variation between seasons in this area is among the most dramatic in the global ocean and this highly dynamic environment makes it an important location to study the effects of changes in pelagic features on fish and invertebrate distributions. Many of the fish and invertebrates in the MAB have evolved to be highly migratory and should respond to the dynamic water column features, which include gradients in temperature, stratification and surface currents (Gong et al. 2010, Shearman \& Lentz 2010). Many of these species are also of great interest to both commercial and recreational fisheries. Though there is high benthic biomass, pelagic species are still very important (Link et al. 2008). The region has a well-developed ocean observation system that integrates data describing these features and, thus, is well suited for this type of research.

\section{Species abundance data}

Abundance estimates for fish and invertebrate species were determined from fall, winter and spring fisheries-independent bottom trawl surveys conducted by NMFS-NEFSC (Table 1, Fig. 1). The survey design and trawl characteristics are described in detail by Azarovitz (1981). Winter cruises occurred in February, spring cruises between March and the beginning of May and fall cruises from the beginning of September through late October. The winter and spring surveys were undertaken when the water column was relatively well mixed compared with fall cruises (Gong et al. 2010). Survey tows were made with a \#36 Yankee trawl $(12.7 \mathrm{~cm}$ stretched mesh opening, $11.4 \mathrm{~cm}$ stretched mesh cod end, $1.25 \mathrm{~cm}$ stretched mesh lining in cod end and upper belly) equipped with rollers and a $10.4 \mathrm{~m}$ wide $\times 3.2 \mathrm{~m}$ high opening. The net was towed at $\sim 3.5$ knots over the bottom for $30 \mathrm{~min}$. The distance a net was towed at each station averaged 1.9 nautical miles (95\% confidence limits, 1.75 to 2.01 nautical miles). Trawls occurred throughout the $24 \mathrm{~h}$ day. We selected a spatial and temporal domain for analysis based upon the availability of remotely sensed data collected by MARACOOS. NEFSC bottom trawl samples collected from February 2003 through October 2007 in the central MAB between the Delmarva Peninsula and the eastern end of Long Island between latitudes 37.14 to $40.85^{\circ} \mathrm{N}$ and longitudes 70.83 to $75.16^{\circ} \mathrm{W}$ (Fig. 1) fit within the domain. Only samples with the full complement of important

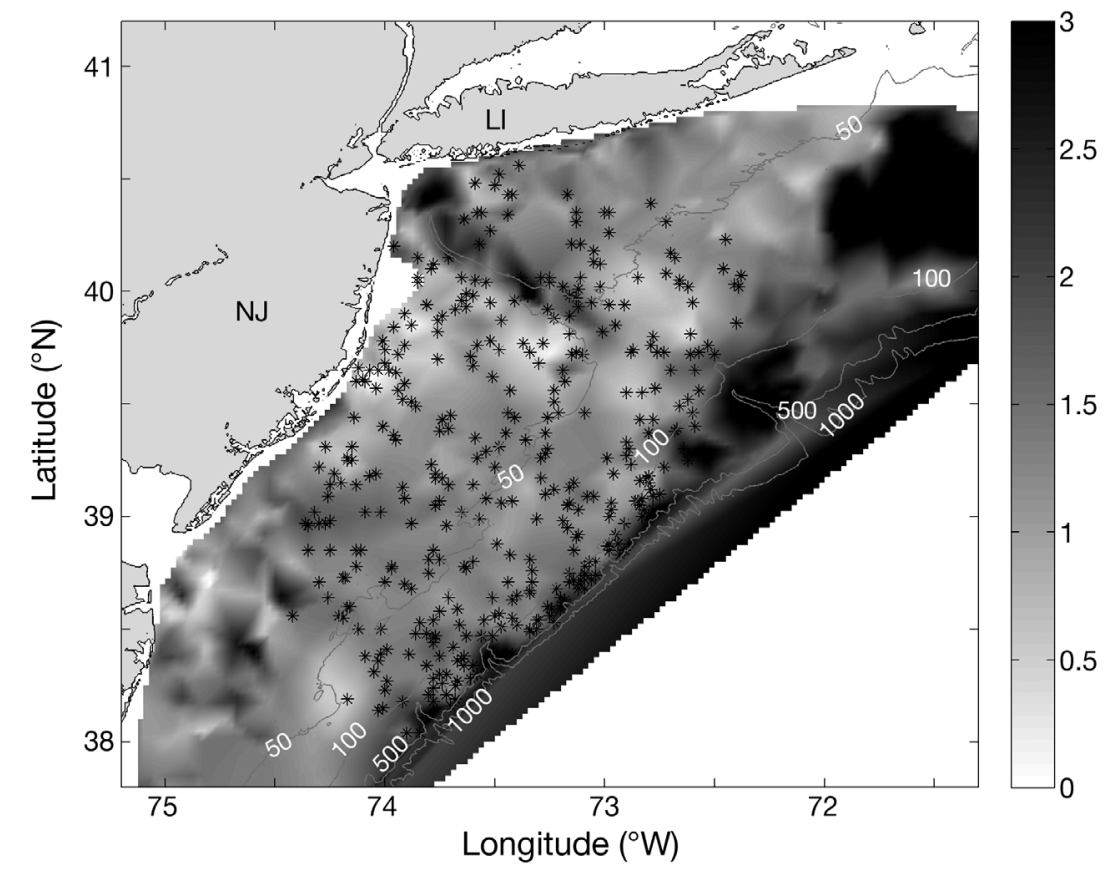

Fig. 1. Locations of sample sites in the Mid-Atlantic Bight (NJ: New Jersey; LI: Long Island) off the Atlantic coast of the USA. The locations of the trawls included in the analysis are shown overlapping a map of sediment grain size on a phi scale, where grain size in $\mathrm{mm}=2^{(- \text {phi })}$ 
Table 1. Common and scientific names (listed alphabetically by the latter) of the 65 species included in the multivariate analysis. Species included were those observed in at least 10 of the trawls used in the analysis

\begin{tabular}{|c|c|c|c|}
\hline Common name & Scientific name & Common name & Scientific name \\
\hline Blueback herring & Alosa aestivalis & Haddock & Melanogrammus aeglefinus \\
\hline Alewife & Alosa pseudoharengus & Atlantic silverside & Menidia menidia \\
\hline American shad & Alosa sapidissima & Offshore hake & Merluccius albidus \\
\hline Northern sand lance & Ammodytes dubius & Silver hake & Merluccius bilinearis \\
\hline Deepbody boarfish & Antigonia capros & Smooth dogfish & Mustelus canis \\
\hline Striated argentine & Argentina striata & Lanternfish, unclassified & Myctophidae \\
\hline Jonah crab & Cancer borealis & Bullnose ray & Myliobatis freminvillei \\
\hline Atlantic rock crab & Cancer irroratus & Longhorn sculpin & Myoxocephalus \\
\hline Black sea bass & Centropristis striata & & octodecemspinosus \\
\hline Shortnose greeneye & Chlorophthalmus agassizi & Atlantic hagfish & Myxine glultinosa \\
\hline Gulf stream flounder & Citharichthys arctifrons & Snake eel, unclassified & Ophichthidae \\
\hline Atlantic herring & Clupea harengus & Summer flounder & Paralichthys dentatus \\
\hline Conger eel, unclassified & Congridae & Fourspot flounder & Paralichthys oblongus \\
\hline Barndoor skate & Dipturus laevis & Butterfish & Peprilus triacanthus \\
\hline Smallmouth flounder & Etropus microstomus & Armored searobin & Peristedion miniatum \\
\hline Red deepsea crab & Geryon quinquedens & Sea lamprey & Petromyzon marinus \\
\hline Witch flounder & Glyptocephalus cynoglossus & Sea scallop & Placopecten magellanicus \\
\hline Blackbelly rosefish & Helicolenus dactylopterus & Bluefish & Pomatomus saltatrix \\
\hline Sea raven & Hemitripterus americanus & Northern searobin & Prionotus carolinus \\
\hline American lobster & Homarus americanus & Striped searobin & Prionotus evolans \\
\hline Northern shortfin squid & Illex illecebrosus & Winter flounder & Pseudopleuronectes \\
\hline Fawn cusk-eel & Lepophidium profundorum & & americanus \\
\hline Little skate & Leucoraja erinacea & Clearnose skate & Raja eglanteria \\
\hline Rosette skate & Leucoraja garmani & Windowpane & Scophthalmus aquosus \\
\hline Winter skate & Leucoraja ocellata & Atlantic mackerel & Scomber scombrus \\
\hline Yellowtail flounder & Limanda ferruginea & Chain dogfish & Scyliorhinus rotifer \\
\hline Atlantic seasnail & Liparis atlanticus & Bobtail, unclassified & Sepiolidae \\
\hline Longfin squid & Loligo paeleii & Spiny dogfish & Squalus acanthias \\
\hline Goosefish & Lophius americanus & Scup & Stenotomus chrysops \\
\hline Ocean pout & Macrozoarces americanus & Tonguefish & Symphurus sp. \\
\hline Longspine snipefish & Macrorhamphosus scolopax & Red hake & Urophycis chuss \\
\hline Grenadier, unclassified & Macrouridae & Spotted hake & Urophycis regia \\
\hline \multirow[t]{2}{*}{ Spider crab, unclassified } & Majidae & White hake & Urophycis tenuis \\
\hline & & Buckler dory & Zenopsis conchifera \\
\hline
\end{tabular}

environmental variables were considered in the final model: an average of 26 samples each winter, 33 each spring and 20 each fall. The 65 species we used for this analysis were observed in at least 10 of the bottom trawls included in the final model (Table 1). Species abundance was normalized to the trawl distance and log transformed for analysis.

\section{Habitat data}

\section{Seabed data}

For the purposes of this study we considered 'seabed' features to be seafloor characteristics, such as topography and sediment grain size, that remain relatively stable over time. We computed topographic seabed habitat characteristics from the 3-arcsecond Coastal Relief Model available from the
National Geophysical Data Center (93 m cell size; www.ngdc.noaa.gov/mgg/coastal/coastal.html)

(Table 2). We used circular-moving window analysis in Geographic Resources Analysis Support System Geographic Information System (GRASS GIS) software to calculate median and SD values of bottom depth, aspect, slope and curvature from the relief model (Neteler \& Mitasova 2008), with a window diameter of $2 \mathrm{~km}$. Profile bottom curvature measured the concavity and convexity of the surface parallel to major axes of slope (Neteler \& Mitasova 2008). Sediment grain sizes (phi) for the trawl samples were selected from a map interpolated from records in the usSEABED data base (Reid et al. 2005). The map of sediment grain size had a spatial resolution of $2.0 \mathrm{~km}$ and was constructed by using sampling bias correction, maximum a posteriori resampling and a spline-in-tension algorithm described in Goff et al. (2006, 2008). 
Table 2. Data sources and possible ecological effects of environmental variables considered in the CCA. Unless otherwise noted, the source of seabed variables is www.ngdc.noaa.gov/mgg/coastal/coastal.html, the source of CTD variables is the shipboard CTD and the sources of remotely sensed data are HF radar for surface current data and Moderate Resolution Imaging Spectrometer (MODIS) for satellite data. Geographic coordinates were recorded at the time of the trawl, and solar elevation was calculated with the maptools library in R. $\mu$ : mean value; PE: potential energy; HF: high frequency; na: not applicable; MAB: Mid-Atlantic Bright

\begin{tabular}{|c|c|c|}
\hline Habitat variable & Spatial resolution & Effect or process \\
\hline Solar elevation & na & Vertical migration/catchability \\
\hline Seasonality & na & Various \\
\hline \multicolumn{3}{|l|}{ Seabed data } \\
\hline Depth $\left(\mu^{\mathrm{a}}\right.$ and $\left.\mathrm{SD}\right)$ & $1.95 \mathrm{~km}$ & Structural/spatial refuge \\
\hline Slope $\left(\mu^{\mathrm{b}}\right.$ and $\left.\mathrm{SD}\right)$ & $1.95 \mathrm{~km}$ & Structural/spatial refuge \\
\hline Aspect (SD) & $1.95 \mathrm{~km}$ & Structural/spatial refuge \\
\hline Profile curvature $(\mu$ and SD) & $1.95 \mathrm{~km}$ & Structural/spatial refuge \\
\hline Sediment grain size $\left(\mu^{\mathrm{a}}\right.$, from usSEABED) & $2 \mathrm{~km}$ & Structural/spatial refuge/enrichment \\
\hline \multicolumn{3}{|l|}{ Pelagic data: CTD } \\
\hline Bottom temperature ${ }^{a}$ & na & Metabolic rate \\
\hline Bottom salinity & na & Proximity to freshwater source \\
\hline Surface salinity $^{\mathrm{b}}$ & na & Proximity to freshwater source \\
\hline Mixed-layer depth & na & Mixing/primary productivity \\
\hline Stratification $^{\mathrm{a}}$ & na & Mixing/primary productivity \\
\hline Simpson's PE (upper 30 m) & na & Mixing/primary productivity \\
\hline \multicolumn{3}{|l|}{ Pelagic data: remotely sensed (HF radar) } \\
\hline $\begin{array}{l}\text { Cross-shelf velocity (raw } \mu \text { and SD, de-tided } \mu \text { and SD, } \\
\text { filtered } \mu^{\text {a }} \text { and SD) }\end{array}$ & $10 \mathrm{~km}$ radius & Advection/movement cost/mixing \\
\hline $\begin{array}{l}\text { Along-shelf velocity (raw } \mu \text { and SD, de-tided } \mu \text { and SD, } \\
\text { filtered } \mu \text { and SD) }\end{array}$ & $10 \mathrm{~km}$ radius & Advection/movement cost/mixing \\
\hline Variance in raw velocities (cross-shelf ${ }^{\mathrm{a}}$ and along shelf) & $10 \mathrm{~km}$ radius & Tidal mixing/episodic forcing \\
\hline Divergence/convergence ( $\mu$ and SD) & $10 \mathrm{~km}$ radius & Upwelling/water column mixing \\
\hline Divergence/convergence tendency ${ }^{\mathrm{a}}$ & $10 \mathrm{~km}$ radius & Upwelling/water column mixing \\
\hline Vorticity ( $\mu$ and SD) & $10 \mathrm{~km}$ radius & Eddy development/retention \\
\hline Vorticity tendency & $10 \mathrm{~km}$ radius & Eddy development/retention \\
\hline \multicolumn{3}{|l|}{ Pelagic data: remotely sensed (satellite) } \\
\hline $\operatorname{SST}\left(\mu^{\mathrm{c}}\right.$ and SD) & $10 \mathrm{~km}$ radius & Metabolic rate/seasonality \\
\hline Chl $a(\mu$ and SD $)$ & $10 \mathrm{~km}$ radius & Primary productivity/organic matter \\
\hline $\begin{array}{l}\text { Water-leaving radiances at 412,443,488, 531, } 551 \\
\text { and } 667 \mathrm{~nm}(\mu \text { and SD) }\end{array}$ & $10 \mathrm{~km}$ radius & $\begin{array}{l}\text { Water clarity and brightness/ } \\
\text { organic matter }\end{array}$ \\
\hline $\begin{array}{l}\text { Water-leaving radiance divided by the maximum } \\
\text { at each trawl: } 412,443,488^{\mathrm{a}}, 531,551^{\mathrm{b}} \text { and } 667 \mathrm{~nm}\end{array}$ & $10 \mathrm{~km}$ radius & Water clarity/organic matter \\
\hline Water mass class & na & Various \\
\hline Gradient strength and distance to gradient (frontal index) & na & Enrichment/concentration \\
\hline
\end{tabular}

Pelagic data

We considered all characteristics of the water column to be 'pelagic', including water temperatures and salinities measured in situ near to the substrata. These characteristics and remotely measured features vary over much shorter timescales than do the seabed variables. We used conductivity, temperature, and depth (CTD) profiles collected during NEFSC bottom trawl surveys to describe water column characteristics in- cluding temperature, salinity and water column structure and stability (Table 2). We considered mixed layer depth (depth at which density was $0.125 \mathrm{~kg} \mathrm{~m}^{-3}$ greater than surface density, Levitus 1982), a stratification index (density difference between $50 \mathrm{~m}$ and the surface), and Simpson's potential energy (PE) anomaly (Simpson 1981) in our analysis. Because the stability index for the entire water column was positively correlated with bottom depth, we used Simpson's PE calculated within the upper $30 \mathrm{~m}$ of the water column. 
Surface features were observed remotely with shore-based and space-based sensors. HF radar (Barrick et al. 1977) provided remotely sensed surface current measurements (Table 2). A network of $\mathrm{HF}$ radars (frequency $=5 \mathrm{MHz}$ ) maintained by MARACOOS measured radial current vectors that were geometrically combined to produce total vector surface current maps each hour with a resolution of $6 \mathrm{~km}$ from the shore to the edge of the continental shelf (www.maracoos.org, Roarty et al. 2010). These data have been used to describe seasonal (Gong et al. 2010) and event-scale surface dynamics (Dzwonkowski et al. 2010) in the MAB. The entire raw time series for each HF radar grid point was detided with a least squares fit of the 5 strongest tidal constituents (M2, S2, N2, K1 and O1). These detided data were then lowpass filtered with a cutoff period of $30 \mathrm{~h}$, which left filtered velocity data that only showed variability on time scales longer than $30 \mathrm{~h}$. We only used data for grid points with $>25 \%$ return over the annual records. Surface divergence (represented as vertical velocity at $1 \mathrm{~m}$ depth) and vorticity (normalized by the local Coriolis parameter of the lowpass filtered fields) were calculated using finite difference (Dzwonkowski et al. 2010, Gong et al. 2010). We considered 1 and $8 \mathrm{~d}$ mean raw, de-tided and filtered cross-shore and along-shore velocities, as well as divergence, vorticity and the variance of the raw fields within $10 \mathrm{~km}$ of each trawl sample in our modeling. To identify species associations with areas where upwelling and downwelling occurred over time scales longer than $8 \mathrm{~d}$ we calculated a seasonal 'divergence tendency' for each year by assigning a new value of -1 to instantaneous divergence (vertical velocity) values that were less than $-0.1 \mathrm{~m} \mathrm{~d}^{-1}$ (downwelling), 0 to values between -0.1 and $+0.1 \mathrm{~m} \mathrm{~d}^{-1}$ (neutral) or +1 to values greater than $+0.1 \mathrm{~m} \mathrm{~d}^{-1}$ (upwelling). These new values were averaged for each grid point to produce a mapped index of upwelling and downwelling potential for each season and year. We calculated divergence tendency for each trawl by averaging all seasonal means within $10 \mathrm{~km}$ of the trawl location. The same processing was performed to generate vorticity tendencies using threshold values of \pm 0.02 . Thresholds were in approximately the 25 th and 75th percentiles of the entire set of values.

Satellite remote sensing provided maps of surface temperature, chlorophyll a ( $\mathrm{chl}$ a) and water-leaving radiance within $10 \mathrm{~km}$ of each NEFSC trawl tow over the previous $24 \mathrm{~h}$ and $8 \mathrm{~d}$ before each bottom trawl tow (Table 2), which helped to fill in some of the gaps in coverage. We used data from the Moderate Resolution Imaging Spectrometer (MODIS) binned to
$1 \mathrm{~km}$ spatial resolution with the standard data quality flags using Seadas v. 5.3 for sea surface temperature (SST) and ocean color (http://oceancolor.gsfc.nasa. gov). Since the seasonal signal in SST is so large in the region, ranging from less than $3^{\circ} \mathrm{C}$ to about $28^{\circ} \mathrm{C}$, especially in shallower water (Shearman \& Lentz 2010), we removed this seasonal variability to develop spatial SST anomalies independent of the strong seasonal signal. We used anomalies of raw SST from monthly 7 yr composites averaged over the entire study site instead of raw SST data. To account for this adjustment we included season as a factor in the analysis. We considered measurements of chlorophyll $\left(\mathrm{mg} \mathrm{m}^{-3}\right)$ and normalized water-leaving radiance (nlw, $\mathrm{W} \mathrm{m}^{-2} \mathrm{st}^{-1} \mu^{-1}$ ) at $412,443,488,531,551$ and $667 \mathrm{~nm}$ (nlw412, nlw443, ... nlw667). In addition to raw channel values, we also considered each wavelength divided by the maximum radiance measured for each survey as a proxy for spectral shape of the water-leaving radiance. In coastal oceans, there are many other optically active constituents in the water that are not captured and contaminate the chlorophyll estimates from space (Preisendorfer 1976). Spectral shape is another source of information that is correlated with the overall optical load of the coastal ocean. Hereafter, we refer to spectral shape (the wavelengths relative to the maximum for each site) as rnlw412, rnlw443, ... rnlw667.

Ensemble clustering was applied to satellite SST and reflectance measured at 490 and $555 \mathrm{~nm}$ to objectively classify water masses. Gradient strengths along frontal boundaries between water masses were determined using the methods described in Oliver et al. (2004) and Oliver \& Irwin (2008). We used maps of gradient strength along frontal boundaries of the 27 water masses identified to compute a frontal index equal to the front strength divided by the distance to the front. Because many of the 27 water masses contained fewer than 5 NEFSC trawl samples, we agglomerated the 27 water masses into 8 using k-means clustering and the satellite data used in the original ensemble clustering. Each of the 8 water masses included at least 20 trawl tows.

Since the species selected for analysis can exhibit day-night differences in behavior, including vertical migration, capture efficiencies in bottom trawls can vary with the time of day of the sampling (Powell et al. 2004). We used the maptools library in R (LewinKoh \& Bivand 2008, R Development Core Team 2008) to calculate solar elevations for the times and locations of each trawl and included these in our model for partial analyses. All of the environmental variables except for season and solar elevation were 
divided into one of 3 categories: CTD (in situ pelagic), IOOS (remotely sensed pelagic) or seabed (Table 2).

\section{Statistical model development}

We used canonical correspondence analysis (CCA) to describe the environmental gradients most strongly related to community variation in the MAB. Following application of principal component analysis to identify highly intercorrelated variables in each variable set, we performed the analysis described in detail below (Fig. 2). We used backward selection of variables within each category of habitat data and with all habitat categories combined to create the final CCA model. We then used partial CCA to determine the relative explanatory value of each category. Finally we mapped habitat gradients extracted from the full CCA and used generalized additive modeling (GAM) analysis of species responses to these gradients.

All statistical analysis was performed with $\mathrm{R}$, a free software used for statistical computing and graphics (R Development Core Team 2008). CCA and partial CCA were conducted using the vegan library, a package with several tools available for various analyses of ecological communities (Oksanen et al. 2008). GAMs identifying nonlinear relationships between intercorrelated environmental variables and between species abundance and environmental gradients were formed with the mgcv library, a package containing routines for GAMs and similar regressions (Wood 2006).

\section{Variable selection for models}

We used CCA because it allowed us to simultaneously ordinate nonlinear species responses to long environmental gradients as opposed to redundancy analysis that assumes linear responses to environmental gradients (McGarigal et al. 2000, Oksanen et al. 2008). This technique identifies environmental variables that can be combined to best explain the total community variation.

We first performed 3 separate CCAs, one for each category of environmental data (seabed, CTD pelagic and remotely sensed pelagic), to identify highly redundant variables and reduce the number of environmental variables in each set. This was followed by a total CCA including season, solar elevation and all significant variables from each initial CCA. We performed backward selection and selected variables with values of $p<0.01$ in Monte Carlo permutation tests. We further reduced variables by only including those with possible mechanistic effects on the physiology or behaviors of the animals (Table 2). For variables that were highly intercorrelated and had the same ecological meanings, the least noisy and most ecologically meaningful variable was used. For intercorrelated

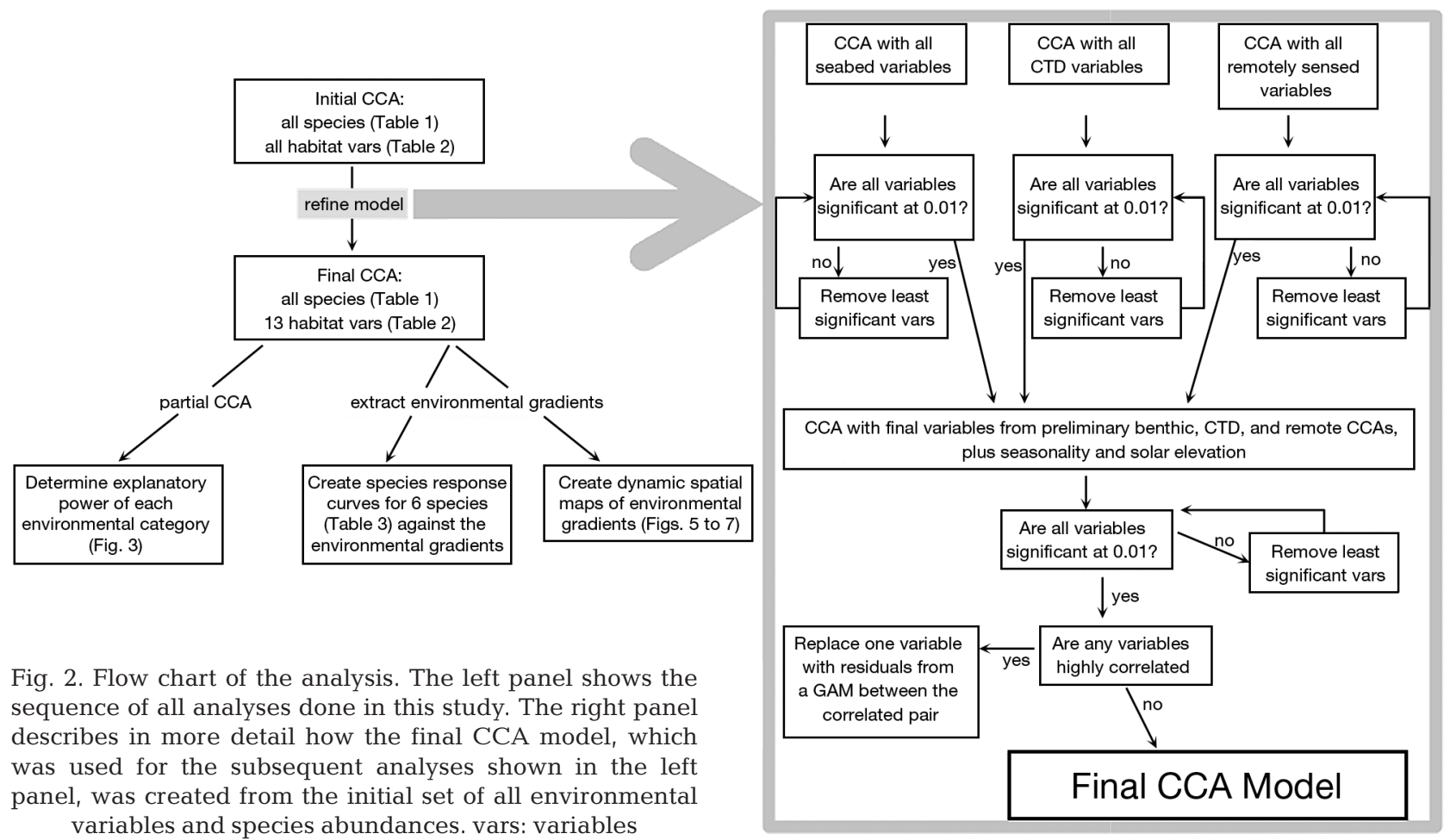


pairs with different implications, one variable in the pair was replaced with residuals from a GAM fit between the intercorrelated pair. Because there was a large skew to the left for depth, we used log-transformed depth in the model. The final CCA model included the 65 species listed in Table 1 and 13 environmental variables - season, 3 seabed variables, 3 CTD variables and 6 remotely sensed variables (Table 2).

\section{Model partitioning}

We determined relative explanatory power of each category of environmental data (seabed, CTD pelagic and remotely sensed pelagic; Table 2) and overlap in explanatory power between categories with partial and constrained CCA using the variables included in the final CCA (Borcard et al. 1992, Cushman \& McGarigal 2002).

Species responses to environmental variability

We used scores for each trawl station along each of the first $3 \mathrm{CCA}$ axes to map the gradients extracted in the ordination and examine the responses of species to them. Color maps of each gradient within each season were derived by applying bilinear interpolation to the station scores on a grid with a cell size of $0.025^{\circ}$ latitude $(2.8 \mathrm{~km})$ by $0.025^{\circ}$ longitude $(2.1 \mathrm{~km})$. To describe species responses to the environmental gradients, we chose 6 species from the 65 included in the CCA that were well described by the ordination (Table 3). These species also represented different latitudinal ranges relative to the Northeast US Continental Shelf Large Marine Ecosystem (north and south) and water column preferences (pelagic fish, pelagic squid and benthic flatfish); these included Atlantic herring Clupea harengus, witch flounder

Table 3. The 6 species analyzed in response to the environmental gradients extracted from the CCA

\begin{tabular}{|c|c|c|c|}
\hline Common name & Scientific name & $\begin{array}{l}\text { Latitudinal } \\
\text { region }\end{array}$ & $\begin{array}{l}\text { Water column } \\
\text { preference }\end{array}$ \\
\hline Atlantic herring & Clupea harengus & Northern & Pelagic fish \\
\hline Witch flounder & $\begin{array}{l}\text { Glyptocephalus } \\
\text { cynoglossus }\end{array}$ & Northern & Benthic flatfish \\
\hline $\begin{array}{l}\text { Northern } \\
\text { shortfin squid }\end{array}$ & Illex illecebrosus & Northern & Pelagic squid \\
\hline Butterfish & Peprilus triacanthus & Southern & Pelagic fish \\
\hline Summer flounder & Paralichthys dentatus & Southern & Benthic flatfish \\
\hline Longfin squid & Loligo paeleii & Southern & Pelagic squid \\
\hline
\end{tabular}

Glyptocephalus cynoglossus, northern shortfin squid Illex illecebrosus, butterfish Peprilus triacanthus, summer flounder Paralichthys dentatus and longfin squid Loligo paeleii. Each of these species is common in the MAB and had relatively high goodness-of-fit scores in the final CCA model. GAM was used to fit a response curve using the relative abundance of each of these 6 species at the trawl stations as the dependent variable against the CCA axis scores for the trawl stations along each of the first 3 gradients derived from the ordination.

\section{RESULTS}

\section{Variable selection}

A total of 13 habitat variables were selected for final analysis based upon correlation structure of the independent variables and the ecological mechanisms they represented. These variables included season, 3 seabed variables (log-transformed depth, bottom slope residuals versus log-transformed depth, sediment grain size), 3 pelagic variables measured in situ with CTDs (bottom temperature, surface salinity residuals versus log-transformed depth, stratification) and 6 remotely sensed pelagic variables $(8 \mathrm{~d}$ mean rnlw488, rnlw551 residuals versus log-transformed depth, SST anomalies and filtered cross-shore velocity, $8 \mathrm{~d}$ variance in raw cross-shore velocity and seasonal divergence tendency).

\section{Community variance partitioning}

The 13 variables included in the final CCA model accounted for $26.0 \%$ of the community variation. When the effects of season were removed from the model, $23.7 \%$ of the community response was explained by the 12 remaining environmental variables. Each of the 3 categories of environmental data considered (seabed, CTD pelagic, remotely sensed pelagic) individually explained approximately the same proportion of this $23.7 \%$ (Fig. 3), but the pelagic characteristics (remotely sensed: $46.9 \%$; CTD: $45.1 \%$ ) explained slightly more than the seabed characteristics (40.9\%). Remotely sensed pelagic variables were redundant with both seabed and pelagic variables measured with CTD 
(16.7 and $16.0 \%$, respectively), while there was little correlation between seabed variables and pelagic characteristics measured with CTD (3.0\%). Redun-

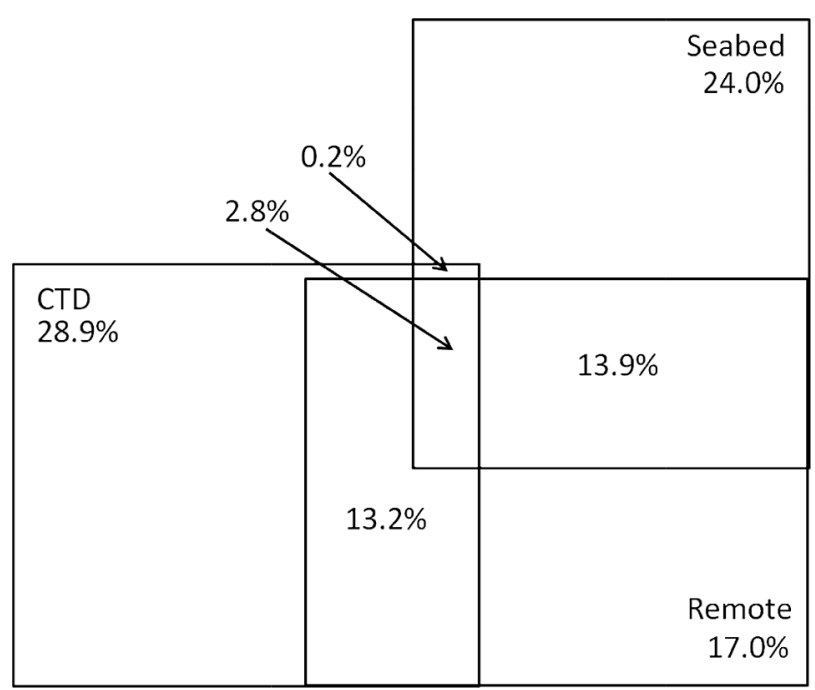

Fig. 3. Relative explanatory power of categories of habitat data. Proportion of the total $23.7 \%$ of the community response explained by spatial variation divided into 3 categories (seabed, CTD pelagic, remotely sensed pelagic) is depicted. Overlap between categories indicates redundancy between those categories. Pelagic categories were as effective at explaining community response as the seabed category was. The remotely sensed category showed high redundancy with both other categories dancy between the remotely sensed category and the seabed category appeared to be primarily due to a correlation between log-transformed depth and the spatial SST anomaly. Redundancy between pelagic habitat measured remotely and in situ with CTD profiles was probably due to correlations between the CTD-derived variables of surface salinity residuals and water column stratification and the remotely sensed variables of cross-shore velocity, variance in cross-shore velocity, and rnlw551 residuals (Fig. 4).

\section{Species response to CCA axes}

The first 3 axes of the final CCA model accounted for $71.3 \%$ of the explained community variation

Table 4. Amount of variation accounted for by the CCA explained by each of the first 3 axes and the most influential variables on each axis

\begin{tabular}{|c|c|c|c|}
\hline $\begin{array}{l}\text { CCA } \\
\text { axis }\end{array}$ & $\begin{array}{c}\% \\
\text { explained }\end{array}$ & $\begin{array}{l}\text { Cumulative } \\
\% \text { explained }\end{array}$ & $\begin{array}{c}\text { Important } \\
\text { habitat variables }\end{array}$ \\
\hline 1 & 39.3 & 39.3 & $\begin{array}{l}\text { SST anomaly } \\
\text { Log-transformed depth }\end{array}$ \\
\hline 2 & 20.7 & 60.0 & $\begin{array}{l}\text { Log-transformed depth } \\
\text { Bottom temperature }\end{array}$ \\
\hline 3 & 13.1 & 73.1 & Stratification \\
\hline
\end{tabular}
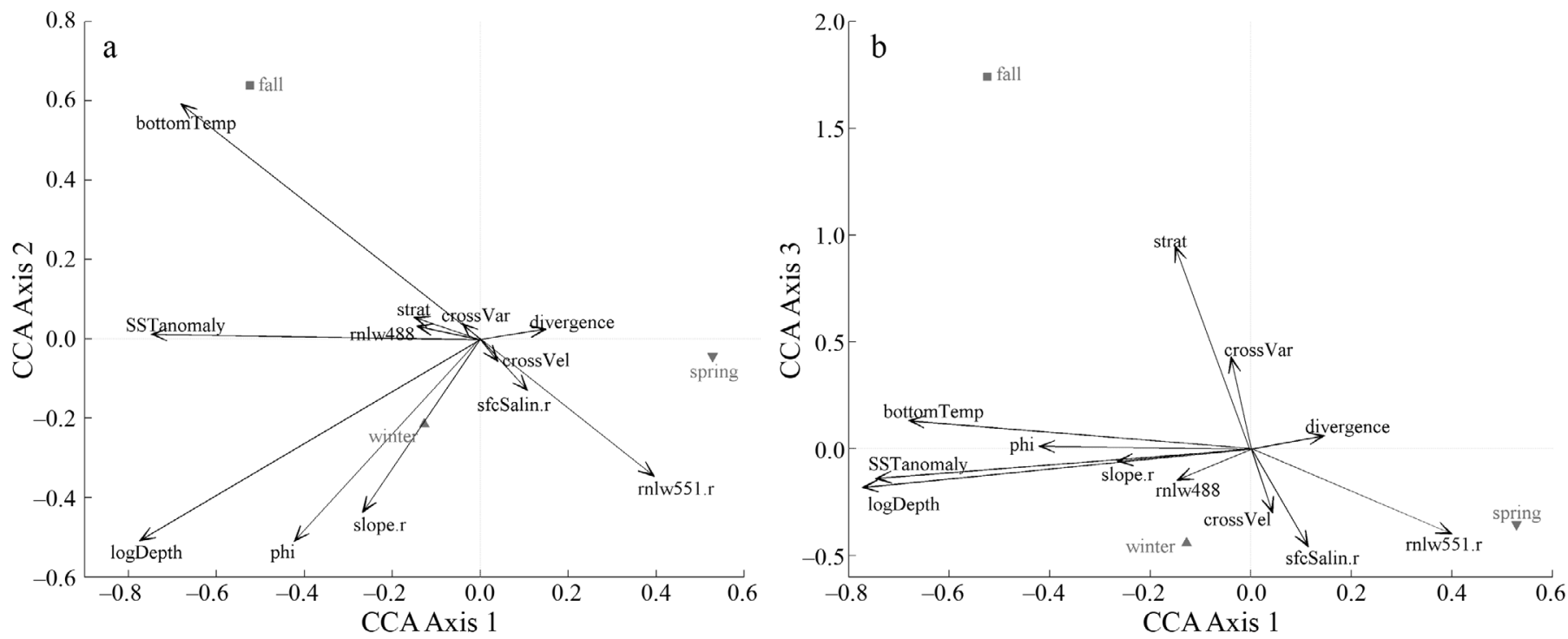

Fig. 4. CCA biplots for the final model. (a) Axes 1 and 2 and (b) Axes 1 and 3 are shown. Points correspond to weighted centroids for each season and arrows correspond to biplot scores for spatial environmental variables (logDepth: log-transformed depth; slope.r: slope residuals versus depth; phi: sediment grain size; bottomTemp: bottom temperature; sfcSalin.r surface salinity residuals versus depth; strat: stratification; rnlw488: water-leaving radiance at $488 \mathrm{~nm}$ relative to the maximum at a site; rnlw551.r: rnlw551 residuals versus depth; SSTanomaly: SST anomaly; crossVel: filtered cross-shore velocity; crossVar: variance in raw cross-shore velocity; divergence: divergence tendency). Variables corresponding to arrows reaching far along an axis are important on that axis 
(Table 4). The remaining axes had about half the explanatory power (or less) compared with any of these 3 axes (Fig. 4). Maps of environmental gradients derived from the CCA and the species response curves to those gradients indicate areas and times the species were most likely to occur in the study area for winter, spring and fall of 2006 (Figs. 5 to 7).

The first axis was defined by a winter/spring cross-shelf gradient. The most influential variables on the first axis (' + ' indicates a positive correlation with axis scores, ' - ' indicates a negative correlation) were log-transformed depth (-), SST anomaly (-), bottom temperature (-), sediment grain size (phi, -) and rnlw551 residuals (+). Axis scores tended to be low across the entire shelf during the fall owing to high SST over shallow water inshore and low SST over deep water farther offshore. In the winter and spring, low SST over shallow inshore water and high SST over deeper offshore water created a gradient with high axis scores close to shore that decreased farther offshore. Atlantic herring and summer flounder were most abundant in areas with high scores on this axis and showed an association with shallow, cold areas with coarse-grained sediment and anomalously high rnlw551 (551 nm is in the green range of the spectrum). Witch flounder, northern shortfin squid and longfin squid all tended to be most abundant at very negative axis values
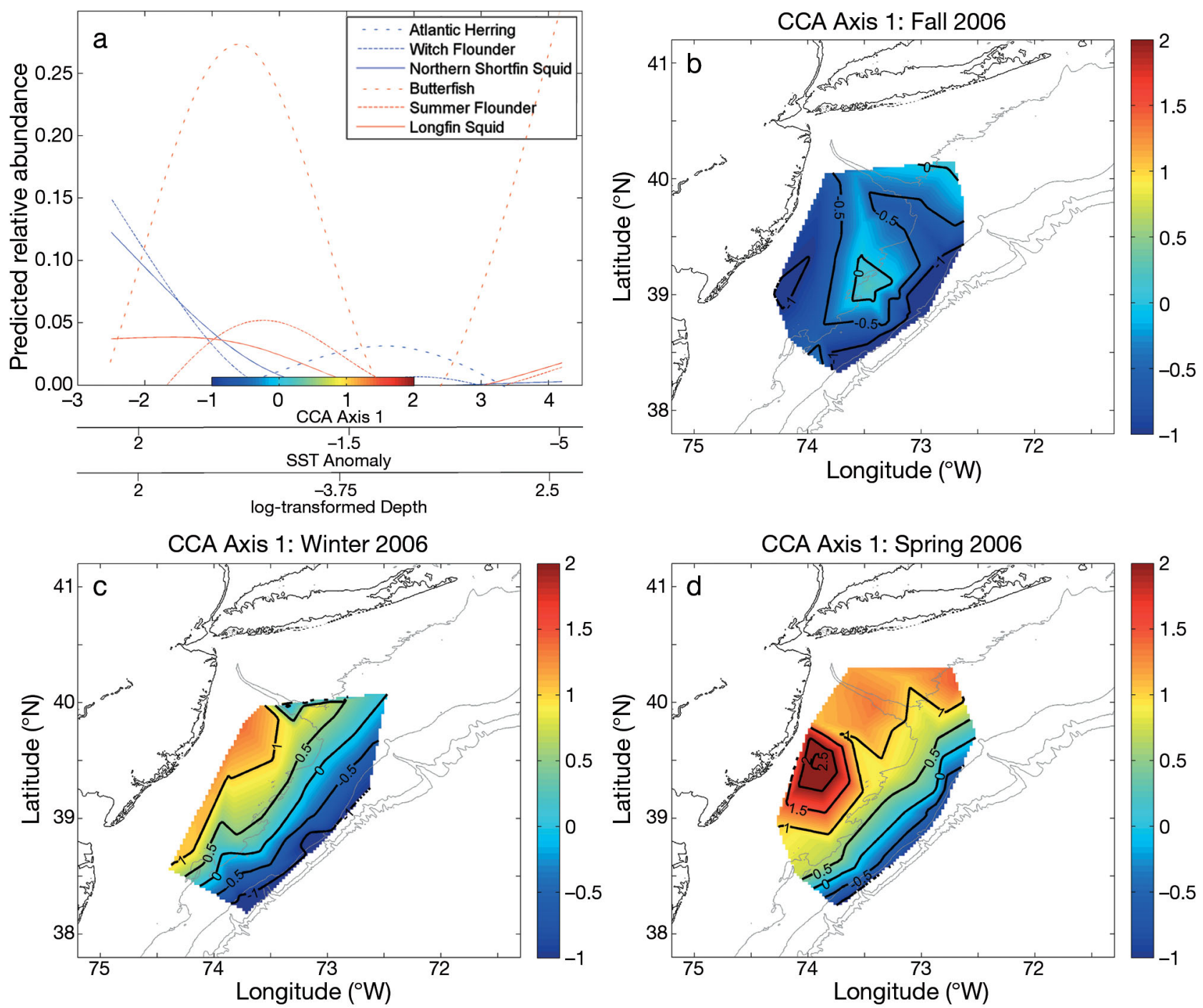

Fig. 5. Response curves and spatial maps for CCA Axis 1. (a) Abundance, relative to the maximum observed abundance, is plotted for 6 species as predicted by a GAM dependent on Axis 1 scores, correlated with SST anomaly and depth (blue: northern; red: southern; solid: pelagic squid; dotted: pelagic fish; dashed: benthic flatfish). Color maps and contours show how Axis 1 scores are distributed spatially for (b) fall, (c) winter and (d) spring of 2006 
(Figs. 4 \& 5). Butterfish and summer flounder were not well explained on this axis.

The second axis was a cross-shelf gradient that was stronger during the fall and mostly consisted of bottom temperature $(+)$ and seabed variables including log-transformed depth (-), sediment grain size (phi, - ) and bottom slope residuals (-). Shallow water with a warm bottom, coarse-grained sediment and an anomalously small slope for that depth produced high scores here. Spatial maps of this axis showed high scores inshore and low scores offshore in the fall (from shallow water with a warm bottom to deep water with a cold bottom). In the winter and spring, bottom temperature and depth balanced each other on the axis and resulted in maps that were neutral across the entire region. Southern species (butterfish, summer flounder, longfin squid) were most abundant where axis values were very positive, while northern species (Atlantic herring, witch flounder, northern shortfin squid) tended to be most abundant where axis values were more negative (Figs. 4 \& 6). Atlantic herring and northern shortfin squid were not well explained on this axis and southern species were better explained than northern species.

The third axis was characterized mostly by stratification (+), but variance in raw cross-shore velocity (+), surface salinity residuals (-), and rnlw551 (-) were also important. Sites with high scores on this axis ex-
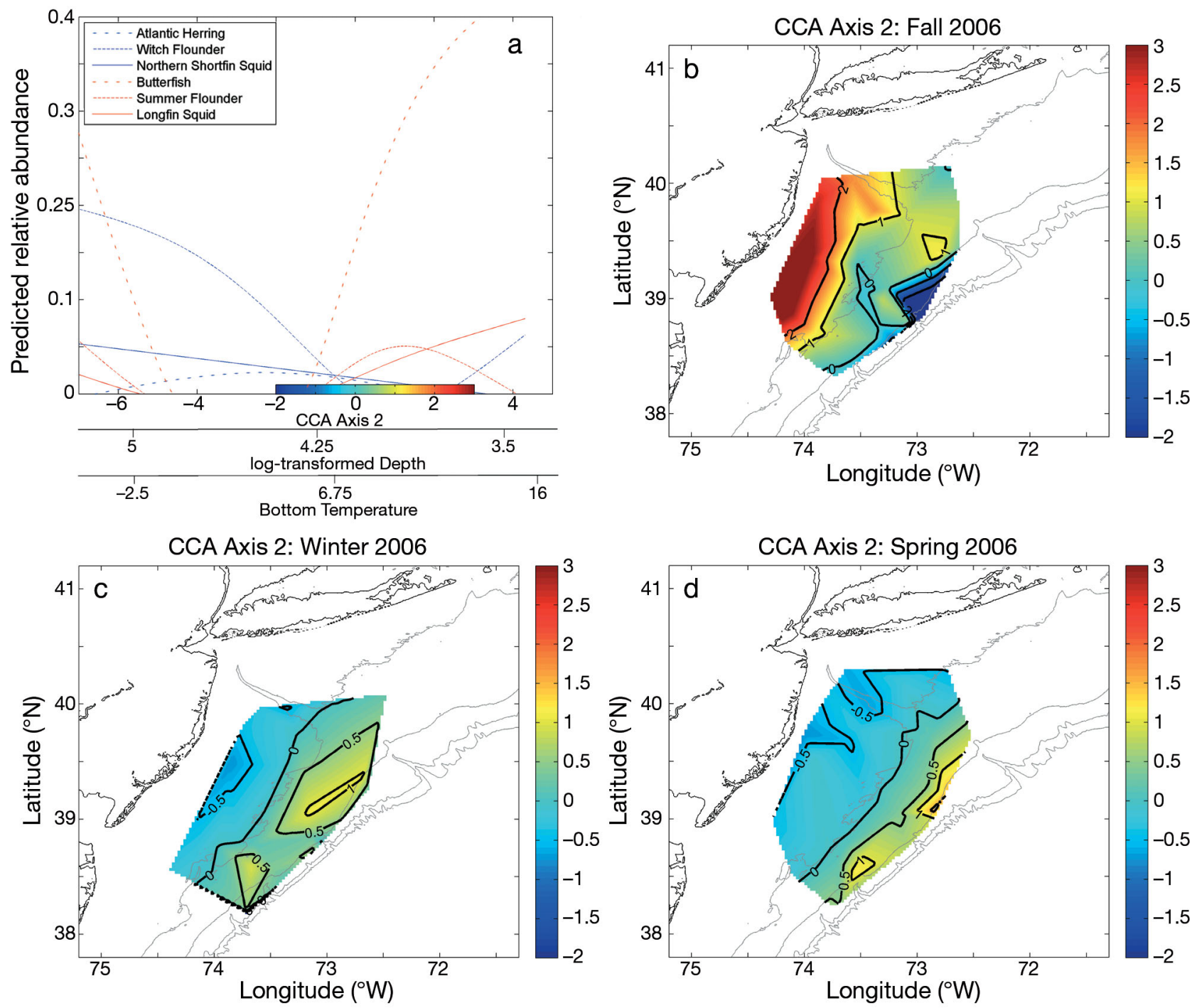

Fig. 6. Response curves and spatial maps for CCA Axis 2. (a) Abundance, relative to the maximum observed abundance, is plotted for 6 species as predicted by a GAM dependent on Axis 2 scores, correlated with depth and bottom temperature (blue: northern; red: southern; solid: pelagic squid; dotted: pelagic fish; dashed: benthic flatfish). Color maps and contours show how Axis 2 scores are distributed spatially for (b) fall, (c) winter and (d) spring of 2006 
hibited high stratification, high variance in cross-shore velocity, and low surface salinity and rnlw551 for that depth. This axis included major environmental factors that all exhibit strong seasonal variation. Fall samples had high values on this axis and were collected in locations where stratification was high, salinity was low, onshore flow was variable and the water was relatively clear. Maps of this gradient in the fall show scores that were low very near the coast but increased rapidly with depth and were high throughout most of the study area. During winter and early spring when the water column was well mixed, scores along this gradient were low throughout the study area. Summer flounder and Atlantic herring were most abundant at low gradient values, while northern shortfin squid was most abundant at high values (Figs. 4 \& 7). Longfin squid, witch flounder, butterfish and Atlantic herring were not well explained on this axis.

\section{DISCUSSION}

We took a community-based multivariate approach to define important environmental gradients in the MAB. We eliminated most of the environmental variables initially considered because they were redundant with other variables or not significant to the model. These factors were further condensed into 2
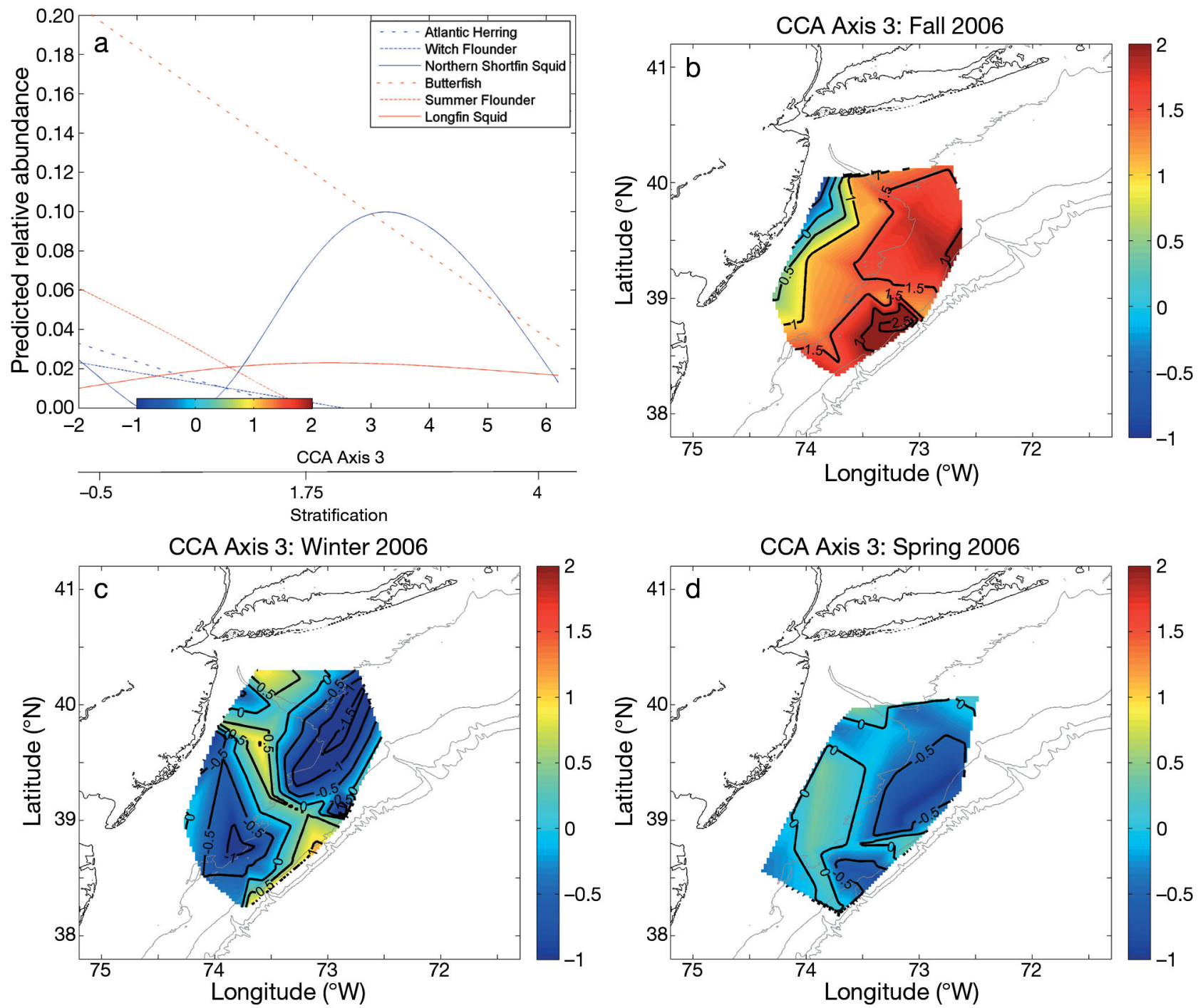

Fig. 7. Response curves and spatial maps for CCA Axis 3. (a) Abundance, relative to the maximum observed abundance, is plotted for 6 species as predicted by a GAM dependent on Axis 3 scores, correlated with stratification (blue: northern; red: southern; solid: pelagic squid; dotted: pelagic fish; dashed: benthic flatfish). Color maps and contours show how Axis 3 scores are distributed spatially for (b) fall, (c) winter and (d) spring of 2006 
major gradients (cross-shelf and seasonal) associated with variations in fish and invertebrate community structure in the MAB. These environmental gradients were relatively well described by the seabed and pelagic features we considered in our analysis. Surface pelagic features measured remotely and integrated into ocean observation systems increased the explanatory power of our model beyond what was traditionally used in marine habitat analyses (seabed and pelagic variables measured with CTD). Furthermore, several important habitat features measured by CTD were correlated with remotely sensed features; this indicates that it may be possible to use remote sensing as a proxy without going to sea. These types of analyses make it possible to look at the ecosystem holistically and avoid evaluating each species independently. Identifying environmental features important to large groups of species should lead to more parsimonious descriptions of essential fish habitat and be useful for defining areas for ecosystem process studies.

Though only a seemingly small percentage of community variation was explained by the CCA $(26 \%)$, several authors argue that total variance explained carries very little meaning in ordinations and that ordinations should be used primarily as graphical tools (Palmer 1993, Oksanen 2011). A multivariate approach used to predict the responses of many species to only a few environmental variables cannot be expected to directly predict species abundances; even a small amount of variance explained still provides valuable information (Palmer 1993, Cushman et al. 2007).

\section{Importance of pelagic habitat}

Current spatial management focuses nearly exclusively on seabed habitat characteristics and features with slow spatial dynamics (Leslie 2005). Bottom structure provides refuge from predators and drag induced by current flow and partially controls the composition and densities of benthic prey. The environmental gradient represented by our second CCA axis was composed almost exclusively of seabed variables; bottom temperature was the only pelagic characteristic important on the axis. Because many species depend on features that vary over scales smaller than the $2 \mathrm{~km}$ grid used in this study, these variables may have been even more powerful in the model if data with finer spatial resolution had been available. However, the pelagic habitat is at least as important for describing community structure in the MAB (Nye et al. 2009), and in our analysis two of the top 3 most explanatory axes of the model were primarily defined by pelagic features. Pelagic features measured in situ with CTD and remotely each explained about as much community variation as the seabed category, and only $24 \%$ of the community variation accounted for was unrelated to the pelagic categories measured with the CTD or remote sensing. The dominant environmental gradient (CCA Axis 1) was described by both seabed and pelagic variables, including temperature and rnlw551. The third axis was defined by a combination of stratification and other processes related to mixing and thus exclusively by pelagic features.

No discernible differences could be distinguished between the responses for benthic flatfish, pelagic fish and pelagic squid to any of the environmental gradients. There may be a northern-southern distinction on the second axis; southern species were more abundant in shallow, warm water $\left(>7^{\circ} \mathrm{C}\right)$, but it is difficult to draw conclusions from this because two out of the 3 northern species were not well explained on this axis. Species responses to environmental gradients reasonably reflected typical species distributions and seasonal migrations. Witch flounder remains in deep water year-round (Cargnelli et al. 1999). Herring was only well explained on the first axis, as they were caught during winter and spring in cold, shallow, green (possibly due to primary productivity) water. During fall, when the second and third axes are well defined, Atlantic herring migrate into colder waters farther north and outside of our study range (Stevenson \& Scott 2005). Northern shortfin squid were most abundant in offshore waters during the winter and spring, and even though they move inshore during the warmer fall months they still remain in relatively deep, stratified waters (Hendrickson \& Holmes 2004). Summer flounder, on the other hand, were observed most often during the fall in warm, inshore waters that are shallow enough to be relatively unstratified (Packer et al. 1999). Longfin squid was most common in warm, deep water during the winter and spring, but was found much farther inshore during the fall in shallow, warm water (Jacobson 2005), similar to the distribution of butterfish (Cross et al. 1999).

It is not surprising to find that marine species respond to pelagic features, given how tightly they are coupled with their fluid environment. Because these species are ectothermic, water column characteristics such as temperature have important effects on their metabolism. They also rely heavily on the productivity of the ecosystem, which in turn depends on several factors, including plankton that are af- 
fected by currents, primary productivity that is dependent on water column stability and other pelagic features that are often confined to the surface ocean. Our results showed that pelagic features were not merely somewhat important, but in fact explained the majority of community variation accounted for by this model and were major factors in two of the most important CCA axes. This supports the concept that seascapes need to be viewed as 3-dimensional environments in which the entire vertical water column is just as important as seabed features.

\section{Ocean observing systems describe pelagic habitat and enhance habitat models}

Remotely sensed variables were important in our model, especially for defining the first and third CCA axes. Axis 1 was heavily weighted with both SST and rnlw551, and rnlw551 and variance in currents were major variables on Axis 3. Remote sensing offers a growing number of possibilities, and several of the other variables that were most important on these axes could potentially be measured and predicted by using remote sensing equipment in the near future.

Many characteristics measured with CTD were well explained by remotely sensed data already available, as evidenced by the high degree of redundancy between remotely sensed surface pelagic features and both seabed and pelagic features measured with CTD; approximately one-third of each of these 2 categories was also described by remotely sensed variables. This suggests that remote-sensing methods for measuring sea surface characteristics are an effective proxy for water column structure, especially during the well-mixed seasons. The redundancy between remotely sensed pelagic features and the seabed features of depth, slope and sediment grain size was most likely due to the inclusion of monthly SST anomalies in the remotely sensed category; SST in deep water is less likely to vary as much as it does in shallow water. Redundancy of remotely sensed surface pelagic features with CTD variables appeared to be due to correlations of cross-shore velocity and variance in velocity, and rnlw551 residuals with stratification and surface salinity residuals. This may be due to mixing processes in regions where surface current velocities are high and variable, which in turn may relate to surface characteristics like salinity and rnlw551 (greenness) that are due to river runoff and mixing of the water column. Although we did not consider differences in redundancy between categories within seasons, it is likely that redundancy varies sea- sonally. In the winter and early spring, surface characteristics are more likely to be similar to bottom characteristics even in relatively deep water because the water column tends to be unstratified. In summer and early fall, however, the water column is highly stratified and surface characteristics are less likely to represent conditions on the bottom (Castelao et al. 2008).

Remotely sensed variables also accounted for an additional $17 \%$ of the explained community variation independently of any redundancy with CTD-derived or seabed features. This indicates that ocean observatories not only provide information about habitat features routinely measured in situ, but also on features not ordinarily measured in situ. Furthermore, 6 habitat variables were included in the remotely sensed category of data: twice as many as in either the CTD or seabed category. While this indicates that there were many remotely sensed variables that contributed important information about habitat, it is important to note that there were also many remotely sensed variables available to be used in this analysis and only a few available in the seabed and CTD categories. The explanatory power of the category was increased simply owing to the number of variables used. The remotely sensed category explained approximately the same amount of community variation as the CTD and seabed categories; even though twice as many variables were included they did not seem to contribute proportionately to the explanation of community variation.

\section{Future directions}

We were able to address and mitigate the effects of some common sources of uncertainty in multivariate ecological models (Cushman et al. 2007), but owing to the limited data available several questions are still left unanswered and deserve further study. Seabed variables in this analysis were assumed to be static over time, but in fact they can be very dynamic over our sampled time scales (Glenn et al. 2008, Harris \& Stokesbury 2010). In addition, the trawls for winter, spring and fall took place over a limited time period and the entire seasons were not covered; no trawls were performed during the summer. Bottom trawl surveys are limited in their ability to represent the entire water column and therefore may not accurately describe distributions of pelagic species. It is also not safe to assume that fish are in a 'preferred' environment. They may be in transit between habitat patches or, if spawning, in (or moving to or from) an environment that is optimal for their young (Katz et 
al. 1994, Terceiro 2007). We only had data available for individuals large enough to be captured in bottom trawls (mostly adults), but to fully understand the ecosystem, information about the abundance and distribution of all life stages is important. Models could also benefit by considering a time lag incorporating past environmental conditions experienced when adults were in younger, more vulnerable life stages. While we believe our major conclusions will hold across all seasons and for the ecosystem as a whole, the more specific details will probably vary depending on the seasons and species in question.

In the future, the ability of remote sensing equipment to augment in situ measurements can be increased further by measuring new characteristics, or by using new applications available with present equipment and by increasing the spatial and temporal coverage of the current equipment (between 2007 and 2008, the HF radar network was expanded to cover the entire MAB). Other ocean observing assets not considered in this study, such as gliders, can also provide more continuous measures of pelagic characteristics (including but not limited to those measured with CTDs) remotely at depths spanning the entire water column, and ensembles of dynamical physical models that assimilate these data have recently been implemented to forecast full vertical water column characteristics (www.maracoos.org/). There are already a number of great data sources, many of which were used in this study, that are useful resources for fisheries research and management. As technology develops further, the possibilities will expand.

Our study was a useful first step toward providing information required for effective space-based ecosystem management. Similar studies in the region have considered large-scale changes in distributions over relatively long time scales (e.g. Link et al. 2002, Nye et al. 2009), while our study emphasized finescale variations in space and time. Further development of our approach can provide techniques for developing dynamic models that describe essential fish habitat for ecologically and economically important species (Manderson et al. 2011) and provide tactical advice for habitat conservation and other important management issues such as by-catch reduction and adaptive management (Kar \& Matsuda 2006). The maps and response curves in Figs. 5 to 7 are an example of what can be done with this type of study. If, with the help of remote sensing technology, maps like these can be created and updated frequently and used to predict the locations of groups of species relevant to fisheries, they may be helpful in developing dynamic management strategies (Game et al. 2009).
Acknowledgements. The authors thank the following agencies for support during this project: NOAA Fisheries and the Environment (FATE NA08NMF450626) for primary support, as well as NASA Biodiversity (NNG06GH75G1/3), NASA New Investigator Program (NNH07ZDA001N), US IOOS Program (MARACOOS NA07NOS4730221, MARACOOS NA10NOS4730014 and MARACOOS NA11NOS0120038) and Delaware Sea Grant (NA10OAR4170084). RU COOL, usSEABED, National Geophysical Data Center and M. Taylor, B. Phelan and S. Lucey at NOAA-NEFSC provided data used in the analysis. We also thank H. Fuchs, J. Manning and anonymous reviewers for their comments and advice.

\section{LITERATURE CITED}

Azarovitz TR (1981) A brief historical review of the Woods Hole Laboratory trawl survey time series. In: Doubleday WG, Rivard D (eds) Bottom trawl surveys. Can Spec Publ Fish Aquat Sci 58:62-67

Bakun A (2010) Linking climate to population variability in marine ecosystems characterized by non-simple dynamics: conceptual templates and schematic constructs. J Mar Syst 79:361-373

Barrick DE, Evans MW, Weber BL (1977) Ocean surface currents mapped by radar. Science 198:138-144

Borcard D, Legendre P, Drapeau P (1992) Partialling out the spatial component of ecological variation. Ecology 73: 1045-1055

Cargnelli LM, Griesbach SJ, Packer DB, Berrien PL, Morse WW, Johnson DL (1999) Essential fish habitat source document: witch flounder, Glyptocephalus cynoglossus, life history and habitat characteristics. NOAA, Natl Mar Fish Serv, NE Fish Sci Cent, Woods Hole, MA. Available at www.nefsc.noaa.gov/nefsc/publications/tm/tm139/ tm139.pdf

Castelao R, Glenn S, Schofield O, Chant R, Wilkin J, Kohut J (2008) Seasonal evolution of hydrographic fields in the central Middle Atlantic Bight from glider observations. Geophys Res Lett 35,L03617, doi:10.1029/2007GL032335

Cross JN, Zetlin CA, Berrien PL, Johnson DL, McBride C (1999) Essential fish habitat source document: butterfish, Peprilus triacanthus, life history and habitat characteristics. NOAA, Natl Mar Fish Serv, NE Fish Sci Cent, Woods Hole, MA. Available at www.nefsc.noaa.gov/publications/ tm/tm145/tm145.pdf

Cushman SA, McGarigal K (2002) Hierarchical, multiscale decomposition of species-environment relationships. Landsc Ecol 17:637-646

Cushman SA, McKenzie D, Peterson DL, Littell J, McKelvey KS (2007) Research agenda for integrated landscape modeling. Gen Tech Rep RMRS-GTR-194. US Department of Agriculture, Forest Service, Rocky Mountain Research Station, Fort Collins, CO

Dzwonkowski B, Lipphardt BL, Kohut JT, Yan XH, Garvine RW (2010) Synoptic measurements of episodic flow events in the central Mid-Atlantic Bight. Cont Shelf Res 30:1373-1386

Fry FEJ (1971) The effect of environmental factors on the physiology of fish. In: Hoar WS, Randall DJ (eds) Fish physiology, Vol 6. Academic Press, New York, NY, p 1-98

Game ET, Grantham HS, Hobday AJ, Pressey RL and others (2009) Pelagic protected areas: the missing dimension in ocean conservation. Trends Ecol Evol 24:360-369

Glenn SM, Jones C, Tawrdowski M, Bowers L and others 
(2008) Glider observations of sediment resuspension in a Middle Atlantic Bight fall transition storm. Limnol Oceanogr 53:2180-2196

Goff JA, Jenkins C, Calder B (2006) Maximum a posteriori resampling of noisy, spatially correlated data. Geochem Geophys Geosyst 7,Q08003, doi:10.1029/2006GC001297

Goff JA, Jenkins CJ, Williams SJ (2008) Seabed mapping and characterization of sediment variability using the usSEABED data base. Cont Shelf Res 28:614-633

Gong D, Kohut JT, Glenn SM (2010) Seasonal climatology of wind-driven circulation on the New Jersey Shelf. J Geophys Res 115,C04006, doi:10.1029/2009JC005520

Harris BP, Stokesbury KDE (2010) The spatial structure of local surficial sediment characteristics on Georges Bank, USA. Cont Shelf Res 30:1840-1853

Hendrickson LC, Holmes EM (2004) Essential fish habitat source document: northern shortfin squid, Illex illecebrosus, life history and habitat characteristics, 2nd edn. NOAA Natl Mar Fish Serv, NE Fish Sci Cent, Woods Hole, MA. Available at www.nefsc.noaa.gov/nefsc/ publications/tm/tm191/tm191.pdf.

Houde ED (2009) Recruitment variability. In: Jakobsen T, Fogarty MJ, Megrey BA, Moksness E (eds) Fish reproductive biology: implications for assessment and management. Wiley, Hoboken, NJ, p 91-171

Jacobson LD (2005) Essential fish habitat source document: longfin inshore squid, Loligo paeleii, life history and habitat characteristics, 2nd edn. NOAA Natl Mar Fish Serv, NE Fish Sci Cent, Woods Hole, MA. Available at www. nefsc.noaa.gov/nefsc/publications/tm/tm193/tm193.pdf

Kar TK, Matsuda H (2006) An overview of bioeconomic analysis and management in fisheries. J Fish Aquat Sci 1: 218-234

Katz CH, Cobb JS, Spaulding M (1994) Larval behavior, hydrodynamic transport, and potential offshore-toinshore recruitment in the American lobster Homarus americanus. Mar Ecol Prog Ser 103:265-273

> Leslie H (2005) A synthesis of marine conservation planning approaches. Conserv Biol 19:1701-1713

Levitus S (1982) Climatological atlas of the world ocean. US Government Printing Office, Washington, DC

Lewin-Koh NJ, Bivand R, Pebesma EJ, Archer E and others (2008) Maptools: tools for reading and handling spatial objects. R package version 0.7-16. R Foundation for Statistical Computing, Vienna

> Link JS, Brodziak JKT, Edwards SF, Overholtz WJ and others (2002) Marine ecosystem assessment in a fisheries management context. Can J Fish Aquat Sci 59:1429-1440

Link J, Overholtz W, O'Reilly J, Green J and others (2008) The northeast U.S. continental shelf energy modeling and analysis exercise (EMAX): ecological network model development and basic ecosystem metrics. J Mar Syst 74:453-474

Lucey SM, Nye JA (2010) Shifting species assemblages in the Northeast US Continental Shelf Large Marine Ecosystem. Mar Ecol Prog Ser 415:23-33

Manderson J, Palamara L, Kohut J, Oliver M (2011) Ocean observatory data is useful for regional habitat modeling of species with different vertical habitat preferences. Mar Ecol Prog Ser 438:1-17

McGarigal K, Cushman S, Stafford S (2000) Multivariate statistics for wildlife and ecology research. Springer-Verlag, New York, NY

Neteler M, Mitasova H (2008) Open source GIS: a GRASS GIS approach, 3rd edn. Springer Science and Business Media, New York, NY
Nye JA, Link JS, Hare JA, Overholtz WJ (2009) Changing spatial distribution of fish stocks in relation to climate and population size on the Northeast United States continental shelf. Mar Ecol Prog Ser 393:111-129

Oksanen J (2011) Multivariate analysis of ecological communities in R: vegan tutorial. Available at http://vegan. r-forge.r-project.org/

Oksanen J, Kindt R, Legendre P, O'Hara B and others (2008) vegan: community ecology package. $\mathrm{R}$ package version 1.15-0. Available at http://cran.r-project.org/, http:// vegan.r-forge.r-project.org/

Oliver MJ, Irwin AJ (2008) Objective global ocean biogeographic provinces. Geophys Res Lett 35,032008, doi: 10.1029/2008GL034238

Oliver MJ, Glenn SM, Kohut JT, Irwin AJ and others (2004) Bioinformatic approaches for objective detection of water masses on continental shelves. J Geophys Res 109, C07S04, doi:10.1029/2003JC002072

Packer DB, Griesbach SJ, Berrien PL, Zetlin CA, Johnson DL, Morse WW (1999) Essential fish habitat source document: summer flounder, Paralichthys dentatus, life history and habitat characteristics. NOAA Natl Mar Fish Serv, NE Fish Sci Cent, Woods Hole, MA. Available at www.nefsc. noaa.gov/nefsc/publications/tm/tm151/tm151.pdf

> Palmer MW (1993) Putting things in even better order: the advantages of canonical correspondence analysis. Ecology 74:2215-2230

> Powell EN, Bonner AJ, Muller B, Bochenek EA (2004) Assessment of the effectiveness of scup bycatch-reduction regulations in the Loligo squid fishery. J Environ Manag 71:155-167

Preisendorfer RW (1976) Hydrologic optics. NOAA Pacific Marine Environmental Laboratory, Honolulu, HI

R Development Core Team (2008) R: a language and environment for statistical computing. R Foundation for Statistical Computing, Vienna. Available at www.R-project.org

Reid JM, Reid JA, Jenkins CJ, Hastings ME and others (2005) usSEABED: Atlantic coast offshore surficial sediment data release. US Geol Surv Data Ser 2005-118, v. 1.0. US Dept Interior, US Geological Survey, Reston, VA

Roarty H, Glenn S, Kohut J, Gong D and others (2010) Operation and application of a regional high-frequency radar network in the Mid-Atlantic Bight. Mar Technol Soc J 44: 133-145

> Shearman RK, Lentz SJ (2010) Long-term sea surface temperature variability along the US east coast. J Phys Oceanogr 40:1004-1017

Simpson J (1981) The shelf-sea fronts: implications of their existence and behaviour. Philos Trans R Soc Lond A Math Phys Eng Sci 302:531-546

Stevenson DK, Scott ML (2005) Essential fish habitat source document: Atlantic herring, Clupea harengus, life history and habitat characteristics, 2nd edn. NOAA, Natl Mar Fish Serv, NE Fish Sci Cent, Woods Hole, MA. Available at www.nefsc.noaa.gov/nefsc/publications/tm/ tm192/tm192.pdf

Terceiro M (2007) Appendix 6. Modeling environmental factors and summer flounder recruitment success. In: SAW 47 Working Paper 11(TOR 6) - Modeling Environmental Factors. NOAA Fisheries, NE Fish Sci Cent, Woods Hole, MA, p 2068-2085

Wood SN (2006) Generalized additive models: an introduction with R. Chapman \& Hall/CRC Press, Boca Raton, FL

Yamashita Y, Tanaka M, Miller JM (2001) Ecophysiology of juvenile flatfish in nursery grounds. J Sea Res 45:205-218 